\title{
Swimming speed performance in coral reef fishes: field validations reveal distinct functional groups
}

\author{
C. J. Fulton
}

Received: 11 October 2006/ Accepted: 6 January 2007/ Published online: 7 February 2007

(C) Springer-Verlag 2007

\begin{abstract}
Central to our understanding of locomotion in fishes are the performance implications of using different modes of swimming. Employing a unique combination of laboratory performance trials and field observations of swimming speed, this study investigated the comparative performance of pectoral and body-caudal fin swimming within an entire assemblage of coral reef fishes (117 species 10 families). Field observations of swimming behaviour identified three primary modes: labriform (pectoral $70 \mathrm{spp}$.), subcarangiform (body-caudal 29 spp.) and chaetodontiform (augmented body-caudal 18 spp.). While representative taxa from all three modes were capable of speeds exceeding $50 \mathrm{~cm} \mathrm{~s}^{-1}$ during laboratory trials, only pectoral-swimmers maintained such high speeds under field conditions. Direct comparisons revealed that pectoral-swimming species maintained field speeds at a remarkable $70 \%$ of their maximum (lab-tested) recorded speed; species using body-caudal fin propulsion maintained field speeds at around $50 \%$ of maximum. These findings highlight a profound influence of swimming mode on performance, with the relative mechanical and energetic efficiency of each swimming mode being of major importance. Combining attributes
\end{abstract}

Communicated by Biology Editor M.I. McCormick.

\section{J. Fulton}

ARC Centre of Excellence for Coral Reef Studies,

James Cook University, Townsville, QLD 4811, Australia

C. J. Fulton $(\bowtie)$

School of Botany and Zoology,

The Australian National University,

Canberra, ACT 0200, Australia

e-mail: christopher.fulton@anu.edu.au of efficiency, maneuverability and speed in one mode of propulsion, pectoral swimming appears to be a particularly versatile form of locomotion, well suited to a demersal lifestyle on coral reefs.

Keywords Gait · Pectoral · Body-caudal · Habitat-use · Energetic

\section{Introduction}

Swimming performance can be crucial for the survival of fishes by affecting their ability to access habitats, avoid predators and acquire food. Such essential daily tasks often require precise movements, bursts of speed, or prolonged periods of swimming depending on the habitat or predator-prey system involved (Videler 1993; Plaut 2001; Castro-Santos 2005). Given that swimming activities may often consume substantial amounts of energy on a daily basis (Feldmeth and Jenkins 1973; Kitchell 1983; Boisclair and Tang 1993; Krohn and Boisclair 1994), swimming can also play a major role in shaping the general health and condition of individuals (Videler 1993). Despite the potential importance, quantitative information on the swimming capabilities of adult fishes remains relatively scarce, particularly for the vast diversity of fishes found on coral reefs (Beamish 1978; Blake 2004).

Central to our understanding of fish locomotion is the behaviour or pattern of body and fin movements used during daily activities. A classification of these swimming behaviours was first introduced by Breder (1926), who categorized the various combinations of body movements into modes, or gaits, and named each mode after a representative taxon (e.g., thunniform 
swimming in tunas based on the genus Thunnus). More recent evaluations have indicated that a wide diversity of fish swimming modes can largely be encompassed within two main functional groups: body-caudal fin (BCF) and median-paired fin (MPF) propulsion (Lindsey 1978; Webb 1994; Blake 2004). BCF modes are powered by movement of the caudal fin and undulation of some proportion of the body, whereas MPF modes are powered by discrete oscillation or undulation of paired or median fins whilst maintaining a rigid body position. Ultimately, these fundamental differences in propulsive style among MPF and BCF modes may translate into significant variations in swimming performance.

Biomechanical appraisals suggest that MPF modes provide greater maneuverability and slow-speed stability, whereas BCF modes impart a greater capacity for high-speed power and acceleration (Alexander 1967; Webb 1998; Weihs 2002). Consequently, MPF swimming is generally thought to be advantageous for fishes interacting with complex habitats such as reefs, while BCF swimming is more suited to open-water cruising (Lindsey 1978; Videler 1993; Webb 1994; Blake 2004). Implicit in these trade-offs between mode and performance is the assumption that MPF-swimming taxa have become specialized for slow-speed maneuvering behaviours, and lack the capacity for maintaining high swimming speeds (Webb 1998; Blake 2004). However, hydrodynamic models have indicated that undulatory $\mathrm{BCF}$ propulsion may incur greater drag and require up to fivefold greater thrust than swimming with a rigid-body MPF mode at a given speed (Lighthill 1969; Webb 1975; Lighthill and Blake 1990; Anderson et al. 2001). Moreover, respirometry evaluations have indicated that MPF-swimming fishes incur relatively low energetic costs during prolonged swimming over a wide range of speeds (Korsmeyer et al. 2002). Collectively, this evidence suggests that MPF-swimming fishes are capable of matching or exceeding the speed performance of BCF fishes, particularly over prolonged time scales (20 s-200 min; sensu Beamish 1978).

Indeed, previous empirical comparisons of swimming speed performance among fishes using BCF and MPF modes have found conflicting trends of comparative speed performance (e.g., Beamish 1978; Walker and Westneat 2002; Blake 2004). Conclusions from such studies have often been limited by differences in methodology and the confounding effects of comparing pelagic BCF and demersal MPF taxa. The present study, therefore, tested the hypothesis that MPFswimming fishes can match or exceed the prolonged swimming speed performance seen in BCF fishes of similar demersal lifestyle. Over 100 species of coral reef fishes from at least three divergent perciform lineages (the Percoidei, Labroidei and Acanthuroidei; Nelson 1994) were included in these analyses, which matched behavioural observations of swimming mode in the field with direct estimates of speed performance under both field and laboratory conditions.

A combined lab-field approach was chosen because methodology can be critical when measuring the swimming speed performance of fishes. Previous studies have used a variety of methods ranging from shortterm burst speed trials $(<20 \mathrm{~s}$ duration) to stepwise and fixed-velocity tests of prolonged performance (>200 min; Beamish 1978; Hammer 1995; Plaut 2001; Blake 2004). Stepwise methods that measure critical swimming speed $\left(U_{\text {crit }}\right)$ have received considerable attention in recent years, with a multitude of studies using $U_{\text {crit }}$ estimates to examine the locomotor capabilities of both larval and adult fishes (e.g., Hartwell and Otto 1991; Lowe 1996; Myrick and Cech 2000; Fisher 2005). The critical speed velocity test was first developed by Brett (1964) as a means of estimating maximum prolonged speeds in fishes by subjecting individuals to stepwise increases in speed until exhaustion (Hammer 1995; Plaut 2001). While $U_{\text {crit }}$ estimates obtained with this method have been correlated with routine field speeds (Plaut 2000; Fisher and Bellwood 2003) and sustained speeds (Brett 1964; Fisher and Wilson 2004) in a limited range of fish taxa, there is still some conjecture as to the relevance of the $U_{\text {crit }}$ metric for speeds displayed by fishes in the field (Hammer 1995; Plaut 2001). For the first time, this study combines estimates of swimming speed taken both in the field and during critical speed trials in a flow tank to examine the comparative speed performance of reef fish taxa utilizing a range of modes.

\section{Materials and methods}

\section{Swimming mode}

Swimming mode was identified for each species using an instantaneous census technique following Fulton et al. (2001), which involved swimming a non-overlapping path over the reef whilst recording the fins being used during the 3-s period following identification of each individual. These censuses encompassed 117 species from ten families: the Acanthuridae, Chaetodontidae, Labridae, Lutjanidae, Nemipteridae, Pomacanthidae, Pomacentridae, Serranidae, Siganidae and Zanclidae. Fin use observations were recorded into four main categories (solely pectoral, caudal, simultaneous 
pectoral-caudal or dorsal-ventral) and taken from a total of 5,285 individuals, with an average $( \pm 1$ SD) of $45.2 \pm 6.9$ observations being taken for each species.

\section{Field speed performance}

Both field and experimental swimming speeds were used to evaluate swimming speed performance in 73 reef fish species from ten families. Field speeds were measured by timing individual fish as they swam undisturbed on the reef in an approximately linear path following the method of Wainwright et al. (2002). The beginning and end of each trial was marked by stopwatch as the fish travelled past noted landmarks on the reef. If an individual deviated markedly from a constant velocity, straight swimming path or began behaving erratically, the trial was discontinued. Immediately after each trial the distance between each landmark was measured to the nearest $5 \mathrm{~cm}$ and recorded, along with the travel time, species and estimated total length (TL) of the individual. As a consequence of using reef landmarks to denote start and end points of distance travelled, only those individuals swimming within the bottom $60 \mathrm{~cm}$ of the water-column were used for these measurements. Field speed observations were taken under calm weather conditions (ambient flow speeds $<5 \mathrm{~cm} \mathrm{~s}^{-1}$ ) to minimise the effects of water motion on swimming speeds. Observer effects were minimised by maintaining at least $6 \mathrm{~m}$ (depending on underwater visibility) between the observer and the fish. A minimum of ten individual observations were taken for each species, with the average $( \pm 1$ SD) travel distance and duration of each field trial being $244 \pm 142 \mathrm{~cm}$ and $7.5 \pm 4.1 \mathrm{~s}$, respectively.

\section{Critical speed performance}

Critical speed performance trials were conducted in a 194-1 re-circulating flow tank of a design following Vogel and LaBarbera (1978), which was transported and set-up within the aquarium complex of the Lizard Island Research Station (LIRS) so that fishes could be sourced from nearby reefs with minimum handling and transportation. Water flow in the tank was generated by a propeller attached to a $0.75 \mathrm{~kW}$ three-phase electric motor, which was connected to a digital speed controller (TECO-Westinghouse TW series) that allowed for $0.1 \mathrm{~Hz}$ incremental changes in motor rotation speed. Water flow speed was calibrated against motor rotation speed $(\mathrm{Hz})$ using digital video tracking of passive particles (unexpanded Styrofoam balls) traveling through the working section. Corner baffles and both upstream (matrix of $12 \mathrm{~mm}$ diameter tubing) and downstream ( $8 \mathrm{~mm}$ acrylic mesh) collimators produced rectilinear flow with minimal variations in flow speed $(6-9 \%)$ across the width $(20 \mathrm{~cm})$ and height $(20 \mathrm{~cm})$ of the $95 \mathrm{~cm}$ long working section. Oxygen depletion of the recirculating water during each swimming trial was minimized by water exchange at a rate of $51 \mathrm{~min}^{-1}$ using seawater taken from the flowthrough aquarium system at LIRS, which draws water from reefs adjacent to where specimens were captured.

Fishes were collected on SCUBA using an ultra-fine monofilament barrier net, transported to aquaria within $2 \mathrm{~h}$, and allowed a minimum $3 \mathrm{~h}$ still-water stabilization before testing. All individuals were swum within $36 \mathrm{~h}$ of capture. While wall effects and refuging cannot be completely eliminated, fish sizes were selected such that their body dimensions were within one third the width and half the height of the working section. PVC half-pipe was placed in the bottom of the working section to minimize flow refuging in the corners of the working section. Critical swimming speed $\left(U_{\text {crit }}\right)$ was measured for each individual using an incremental velocity test following Brett (1964). After transfer and acclimation to the flow tank, the fish was subjected to an initial flow speed of $15 \mathrm{~cm} \mathrm{~s}^{-1}$ for $30 \mathrm{~min}$. Step-wise increases in flow speed $(\sim 0.5$ body lengths $\mathrm{s}^{-1}$-henceforth $\left.\mathrm{BL} \mathrm{s}{ }^{-1}\right)$ were then made every 15 min until the fish could no longer hold position in the working section and became impinged on the downstream mesh. The average $( \pm 1 \mathrm{SD})$ critical speed trial duration was $139 \pm 41.4 \mathrm{~min}$. Each individual was tested only once, with a minimum of three individuals from each species being tested. All fishes were euthanased on completion of the experimental trial for measurement of total length (TL), body depth and width (excluding fins), and mass.

\section{Calculations and statistical analyses}

Raw fin use frequencies in each category were converted to proportional use per species to account for differences in the total number of observations recorded for each species. Patterns of fin use among species were then explored using a correspondence analysis (CA) of the log transformed proportional fin use data from 117 species, following Greenacre (1993). Similarities in fin use among species were then further examined by hierarchical clustering of the transformed fin use data using the unweighted pair group method of averaging (UPGMA), with the allocation of species into each of the major clusters being confirmed by nonhierarchical k-means clustering (Sokal and Rohlf 1995). 
Individual critical swimming speed $\left(U_{\text {crit }}\right)$ values were calculated using the formula of Brett (1964):

$U_{\text {crit }}=U+\left[U_{\mathrm{i}}\left(t / t_{\mathrm{i}}\right)\right]$,

where $U=$ penultimate speed, $t=$ time swum in final velocity increment, $t_{\mathrm{i}}=$ set time interval of each velocity increment $(15 \mathrm{~min})$, and $U_{\mathrm{i}}=$ velocity increment $\left(0.5 \mathrm{BL} \mathrm{s}^{-1}\right)$. Adjustments for solid blocking effects were then made to swimming speed estimates for each individual following the equations of Bell and Terhune (1970) and Korsmeyer et al. (2002):

$U_{\mathrm{F}}=U_{\mathrm{T}}\left(1+\varepsilon_{\mathrm{S}}\right)$,

where $U_{\mathrm{F}}$ is the corrected flow speed, $U_{\mathrm{T}}$ the flow speed taken during calibration of the flume without a fish in the working section, and $\varepsilon_{\mathrm{S}}$ the solid blocking effect, which was calculated for each individual as:

$\varepsilon_{\mathrm{S}}=\tau \lambda\left(A_{\mathrm{O}} / A_{\mathrm{T}}\right)^{3 / 2}$,

where $\tau$ is a dimensionless factor based on the flow tank cross-sectional shape (0.8), $\lambda$ a shape factor for the test fish, $A_{\mathrm{O}}$ the maximum cross-sectional area of the test fish, and $A_{\mathrm{T}}$ the cross-sectional area of the flow tank working section. Shape factor for the test fish was calculated as $\lambda=0.5$ (total length/body thickness), with body thickness being calculated as the average of body depth and width. Cross-sectional area of the test fish was then calculated as an ellipse using the body depth and width measurements. The fractional crosssectional area of the flow tank working section occupied by test subjects $\left(A_{\mathrm{O}} / A_{\mathrm{T}}\right)$ was within the range $0.3-4.7 \%$.

Body size effects were minimised in swimming speed estimates by using individuals of similar mean TL (within 6\%) in both the experimental and field speed measurements for a given species. Two exceptions to this were Naso and Plectropomus spp. whose average size in the field ( $>20 \mathrm{~cm}$ TL) was too large to be swum in the flow tank (16 cm TL limit). Among-species differences in size were further minimised by calculating swimming speed residuals from the linear regression of speed against TL, using mean values of speed and TL from each species (Reist 1985; Wainwright et al. 2002). Species were grouped into swimming modes according to the outcomes from the fin use analyses outlined above. Relationships between field and critical speed performance were examined for each swimming mode through linear regressions of field speed residual against critical speed residual, using the 73 species for which both speed metrics were recorded. These linear regressions of field versus critical speed residuals were then compared among modes using an $F$ test analysis and GT2 multiple comparison of regression coefficients following Sokal and Rohlf (1995). Comparative field-experimental performance was further evaluated by dividing mean field speed by mean $U_{\text {crit }}$ for each species, then averaging these proportions across all species in a given mode to identify field performance as a relative percentage of experimental performance in each mode.

\section{Results}

Swimming mode

Three main modes of fin use were recorded from in situ observations across the ten families: pectoral, simultaneous pectoral-caudal, and caudal swimming (Table 1). Only two of the 5,285 individuals observed displayed dorsal-ventral fin use, and therefore, this category was excluded from further analyses. Correspondence analysis of fin use in the remaining three categories revealed a major separation of taxa according to proportional use of either pectoral (CA1) or caudal propulsion (CA2, Fig. 1). Nonhierarchical (k-means) cluster analysis confirmed the species groupings found in the three main clusters from a UPGMA hierarchical analysis of proportional fin use, which grouped 70, 29, and 18 species into each of the pectoral, pectoral-caudal and caudal modes, respectively (Fig. 1). With only one exception (Stegastes, which was divided amongst the pectoral and pectoral-caudal groups), all 52 genera were assigned exclusively to a single mode category, which resulted in some families being divided amongst two modes (Table 1; Fig. 1). Examination of proportional fin use within each of these groups revealed they included taxa that used a particular fin category in more than half of the individuals observed (Table 1).

\section{Swimming speed performance}

A wide range of field and critical swimming speed performances within and among the three swimming modes were revealed from 1,845 field and 291 experimental speed measurements (Table 2; Fig. 2). In terms of absolute field and experimental speed (in units of $\mathrm{cm} \mathrm{s}^{-1}$ ), pectoral-swimming taxa displayed higher averages overall, with considerable overlap in the range of experimental speeds amongst the three modes (Table 2; Fig. 2). Under field conditions, however, 
Table 1 Proportional frequency of fin use by coral reef fishes from ten families, arranged by family and genus across the three main groups identified by UPGMA and k-means clustering (Fig. 1)

\begin{tabular}{|c|c|c|c|c|}
\hline & Pectoral & Pectoral-caudal & Caudal & $n$ \\
\hline \multicolumn{5}{|l|}{ 1. Pectoral } \\
\hline \multicolumn{5}{|l|}{ Acanthuridae } \\
\hline Acanthurus & 0.99 & 0.01 & & 290 \\
\hline Ctenochaetus & 1.00 & & & 101 \\
\hline Zebrasoma & 1.00 & & & 68 \\
\hline \multicolumn{5}{|l|}{ Labridae } \\
\hline Anampses & 1.00 & & & 38 \\
\hline Bodianus & 1.00 & & & 61 \\
\hline Cheilinus & 1.00 & & & 165 \\
\hline Choerodon & 1.00 & & & 7 \\
\hline Cirrhilabrus & 1.00 & & & 7 \\
\hline Coris & 1.00 & & & 51 \\
\hline Epibulus & 1.00 & & & 63 \\
\hline Gomphosus & 1.00 & & & 136 \\
\hline Halichoeres & 1.00 & & & 408 \\
\hline Hemigymnus & 1.00 & & & 114 \\
\hline Hologymnosus & 1.00 & & & 9 \\
\hline Labrichthys & 1.00 & & & 34 \\
\hline Labroides & 1.00 & & & 61 \\
\hline Macropharyngodon & 1.00 & & & 55 \\
\hline Novaculichthys & 1.00 & & & 43 \\
\hline Oxycheilinus & 1.00 & & & 82 \\
\hline Pseudocheilinus & 1.00 & & & 11 \\
\hline Stethojulis & 1.00 & & & 103 \\
\hline Thalassoma & 1.00 & & & 347 \\
\hline \multicolumn{5}{|l|}{ Pomacanthidae } \\
\hline Pomacanthus & 0.69 & 0.31 & & 104 \\
\hline \multicolumn{5}{|l|}{ Pomacentridae } \\
\hline Abudefduf & 0.98 & 0.01 & 0.01 & 91 \\
\hline Acanthochromis & 0.99 & 0.01 & & 151 \\
\hline Amblyglyphidodon & 1.00 & & & 107 \\
\hline Amphiprion & 1.00 & & & 31 \\
\hline Chromis & 1.00 & & & 158 \\
\hline Chrysiptera & 0.95 & 0.05 & & 123 \\
\hline Dascyllus & 0.94 & 0.06 & & 31 \\
\hline Neoglyphidodon & 0.64 & 0.36 & & 50 \\
\hline Neopomacentrus & 1.00 & & & 74 \\
\hline Pomacentrus & 0.95 & 0.05 & & 457 \\
\hline Premnas & 1.00 & & & 3 \\
\hline Stegastes (apicalis) & 0.75 & 0.25 & & 55 \\
\hline \multicolumn{5}{|l|}{ Zanclidae } \\
\hline Zanclus & 1.00 & & & 36 \\
\hline \multicolumn{5}{|l|}{ 2. Pectoral-caudal } \\
\hline \multicolumn{5}{|l|}{ Chaetodontidae } \\
\hline Chaetodon & 0.04 & 0.90 & 0.06 & 589 \\
\hline Chelmon & 0.17 & 0.83 & & 18 \\
\hline Heniochus & 0.20 & 0.80 & & 30 \\
\hline \multicolumn{5}{|l|}{ Nemipteridae } \\
\hline Scolopsis & 0.08 & 0.64 & 0.28 & 14 \\
\hline \multicolumn{5}{|l|}{ Pomacanthidae } \\
\hline Centropyge & 0.06 & 0.89 & 0.05 & 152 \\
\hline Pygoplites & 0.43 & 0.57 & & 30 \\
\hline \multicolumn{5}{|l|}{ Pomacentridae } \\
\hline Dischistodus & 0.22 & 0.78 & & 9 \\
\hline Plectroglyphidodon & 0.43 & 0.55 & 0.02 & 58 \\
\hline Stegastes (nigricans) & 0.27 & 0.55 & 0.18 & 11 \\
\hline \multicolumn{5}{|c|}{ 3. Caudal } \\
\hline Acanthuridae & & & & \\
\hline Naso & 0.01 & 0.01 & 0.98 & 157 \\
\hline
\end{tabular}

Table 1 continued

\begin{tabular}{lllll}
\hline & Pectoral & Pectoral-caudal & Caudal & $n$ \\
\hline $\begin{array}{l}\text { Lutjanidae } \\
\text { Lutjanus }\end{array}$ & & & & \\
$\begin{array}{l}\text { Serranidae } \\
\text { Cephalopholis }\end{array}$ & 0.04 & 0.11 & 0.93 & 13 \\
$\begin{array}{l}\text { Epinephelus } \\
\text { Plectropomus }\end{array}$ & 0.02 & 0.07 & 0.85 & 85 \\
$\quad$ Variola & & & 0.93 & 15 \\
Siganidae & & 0.02 & 0.93 & 60 \\
$\quad$ Lo & & 0.07 & 0.98 & 72 \\
Siganus & 0.01 & 0.08 & 0.91 & 270 \\
\hline
\end{tabular}

pectoral-swimming taxa maintained a wide range of swimming speeds, while the maximum field speeds of pectoralcaudal and caudal-swimming taxa were limited to an absolute speed of $40 \mathrm{~cm} \mathrm{~s}^{-1}$ or below (Table 2; Fig. 2). Evidence of allometric effects in the relationship between average total length and swimming speed performance of species (Fig. 3) were removed by residualisation, with no significant correlation between total length and the swimming speed residuals of species for both field (Pearson's 0.001, $P=0.99, n=73$ ) and experimental (Pearson's $-0.01, P=0.94, n=73$ ) measures.

Differences in the comparative field-critical speed performance amongst modes were confirmed by the relationship between field and critical speed residuals for each mode (Fig. 4). While there was a strong relationship between field and critical swimming speeds (Table 2), the specific linear relationships were found to be significantly different between the three modes by an $F$ test comparing their slopes $\left(F_{2,55}=\right.$ 4.91, $P<0.02$ ). Post-hoc (GT2) comparisons grouped the regressions of pectoral-caudal and caudal-swimming taxa together, but separated the pectoral-swimming relationship from the other two modes (Fig. 4). Direct comparisons between absolute field and experimental speeds revealed that pectoral-swimming species tended to display a field speed which was $68 \pm 2 \%$ (average $\pm 1 \mathrm{SE}$ ) of the speed attained under experimental conditions, whereas field speeds in pectoral-caudal and caudal-swimming species were an average of $44 \pm 2$ and $48 \pm 4 \%$ of their experimental speeds, respectively. There were a number of marked outliers within each mode, with the pectoral-swimming species Acanthurus triostegus and Acanthurus lineatus, and the pectoral-caudal species Chaetodon trifascialis displaying field performances that appeared to be considerably higher than expected from the general field-lab performance relationship for each mode (Fig. 4). 
Fig. 1 Correspondence analysis (CA) biplot of swimming behaviours in 117 species of coral reef fishes from ten families. Filled squares represent the ordination of each of the three behaviour categories; small open circles represent the vector position of each species. Larger circles represent swimming behaviour groups according to UPGMA hierarchical analysis and k-means clustering

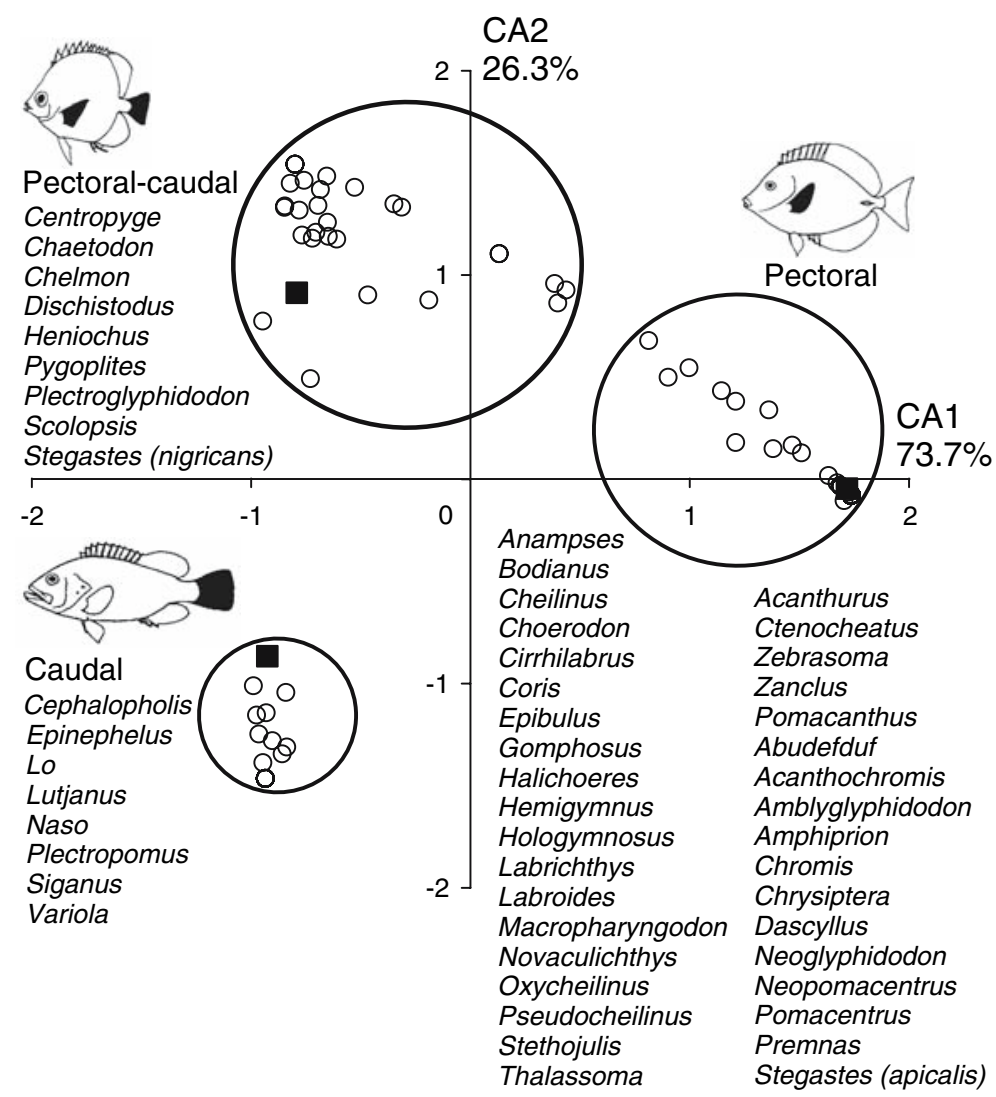

Table 2 Range of field and experimental $\left(U_{\text {crit }}\right)$ speeds and mean total length (TL) for coral reef fishes using each of three swimming modes

\begin{tabular}{|c|c|c|c|c|c|}
\hline & Mean TL $(\mathrm{cm})$ & Mean $\pm \mathrm{SE}\left(\mathrm{cm} \mathrm{s}^{-1}\right)$ & $\operatorname{Min}-\max \left(\mathrm{cm} \mathrm{s}^{-1}\right)$ & $r^{2}$ & $b$ \\
\hline \multicolumn{6}{|l|}{ Pectoral } \\
\hline Field speeds & 11.3 & $31.7 \pm 1.9$ & $9.2-68.8$ & & \\
\hline Experimental speeds & 10.7 & $56.0 \pm 1.8$ & $28.4-82.4$ & 0.52 & 0.83 \\
\hline \multicolumn{6}{|l|}{ Pectoral-caudal } \\
\hline Field speeds & 10.6 & $25.9 \pm 1.0$ & $19.3-35.8$ & & \\
\hline Experimental speeds & 9.8 & $52.8 \pm 2.8$ & $32.5-77.5$ & 0.40 & 0.25 \\
\hline \multicolumn{6}{|l|}{ Caudal } \\
\hline Field speeds & 20.5 & $24.3 \pm 1.9$ & $14.7-39.0$ & & \\
\hline Experimental speeds & 13.4 & $48.6 \pm 4.5$ & $24.0-59.3$ & 0.24 & 0.22 \\
\hline
\end{tabular}

Slope $(b)$ and $r$ squared $\left(r^{2}\right)$ values for the linear regression between field and critical speed residuals are indicated for each mode (see Fig. 4)

All regressions were significant $P<0.01$

\section{Discussion}

Swimming mode classifications based on the different body and fin structures used by fishes are central to our understanding of fish locomotion. Both theoretical and empirical evaluations have suggested fundamental differences between swimming modes in terms of manoeuvrability, stability and speed performance (Alexander 1967; Weihs 1989; Webb 1994; Blake 2004). Consequently, fishes utilising body and caudal fin (BCF) propulsion are generally accepted as dominant swimming speed performers over prolonged and sustained time periods, whilst median-paired fins (MPF) swimming sacrifices speed performance for increased slow-speed manoeuvrability (Alexander 1967; Webb 1994; Blake 2004). For the first time, this study provides direct empirical evidence that MPF-swimming fishes can match and exceed the swimming speed performance of BCF-swimming taxa in both the field and laboratory. Moreover, this study identified a strong 


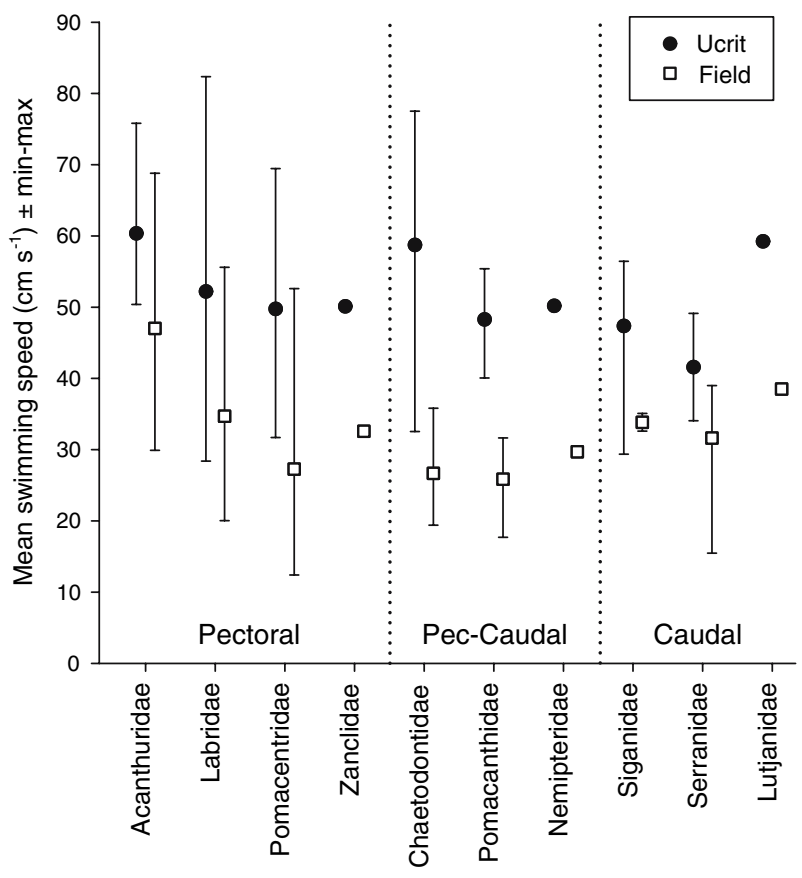

Fig. 2 Range of experimental $\left(U_{\text {crit }}\right)$ and field speeds recorded in ten reef fish families, arranged according to the predominant swimming mode in each family. Each value is the mean swimming speed bounded by the slowest and fastest mean values for a species in that family. Note that only those families, which have predominantly pectoral-swimming species display absolute field speeds exceeding $40 \mathrm{~cm} \mathrm{~s}^{-1}$

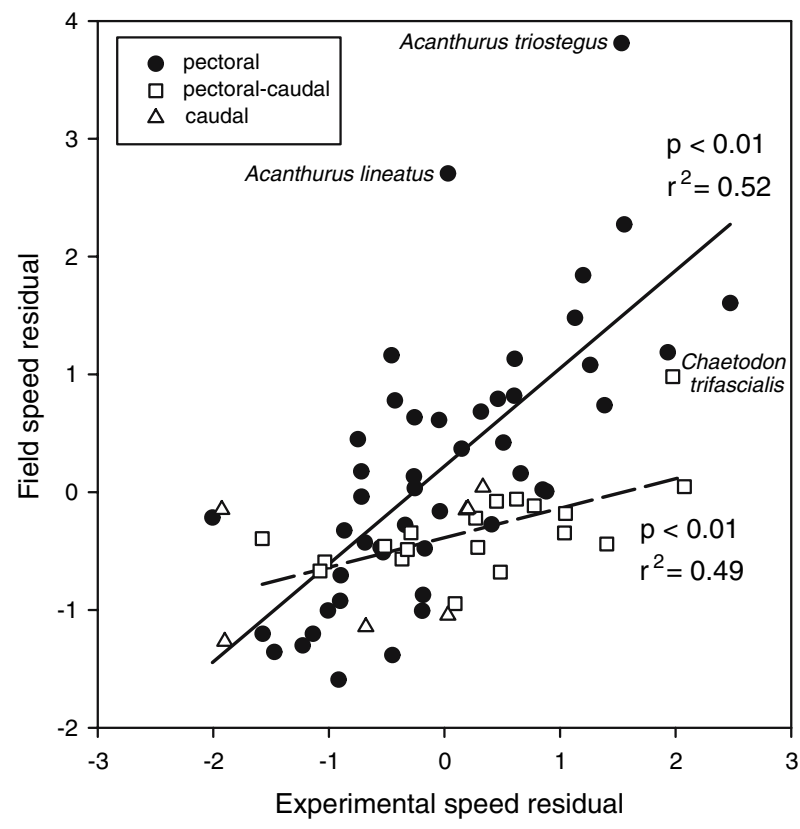

Fig. 4 Relationship between field and critical swimming speed performance in 73 species of coral reef fishes. Both axes have been corrected for body size; high positive residuals represent high speeds for a given size. Solid line represents the linear relationship for labriform taxa. Dashed line represents the pooled linear relationship (grouped by GT2 post-hoc analysis) for pectoral-caudal and caudal-swimming taxa
Fig. 3 Relationship between total length and swimming speed in terms of both absolute speed $\left(\mathrm{cm} \mathrm{s}^{-1}\right)$ and body lengths per second $\left(\mathrm{BL} \mathrm{s}{ }^{-1}\right)$ based on laboratory estimates of critical swimming speed $(\mathbf{a}, \mathbf{b})$ and field speed (c, d). Each set of values is averages for 73 species of coral reef fishes
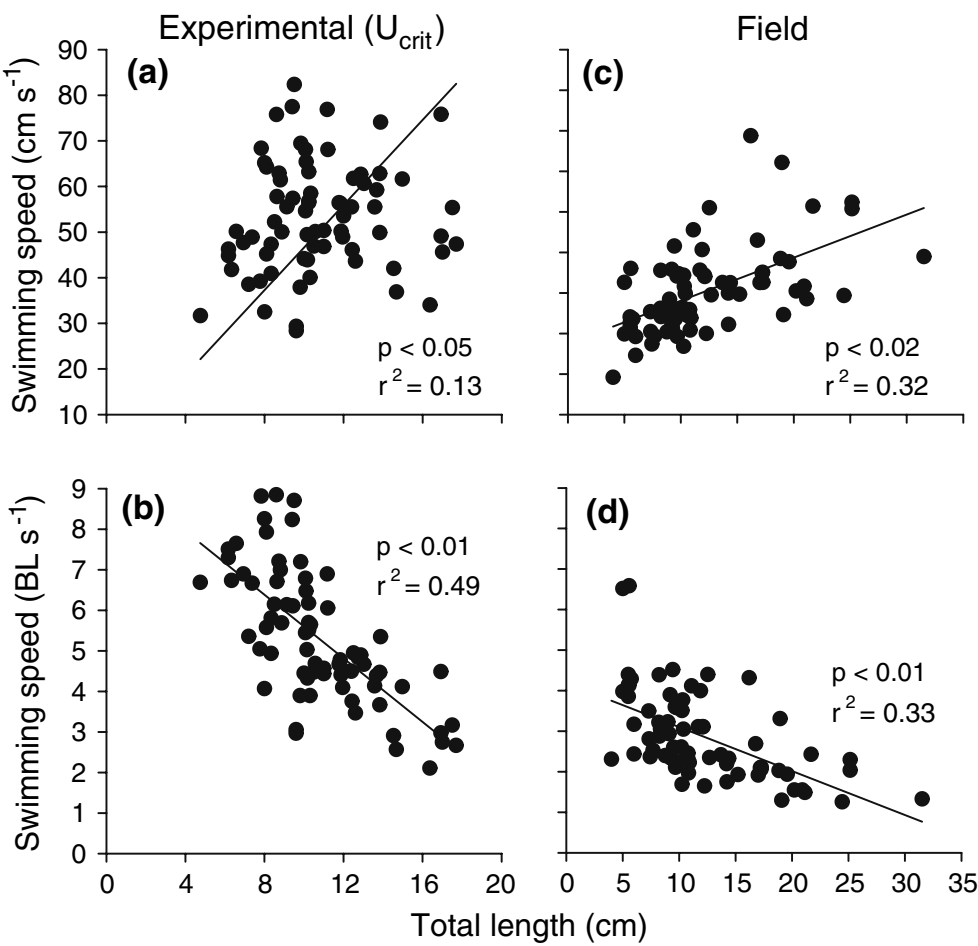
relationship between laboratory and field measures of swimming speed performance that has direct applications for both past and future studies of swimming performance in reef fishes.

Swimming mode utilisation in coral reef fishes

Field observations in the present study identified the swimming modes being used in an entire assemblage of coral reef fishes, confirming previous predictions that demersal reef fish taxa primarily use an MPF mode (Breder 1926; Lindsey 1978; Webb 1984, 1994). Three primary swimming modes were identified in this coral reef fish assemblage based on field observations of 117 species from ten families, with two corresponding with the traditional classifications of Labriform (pectoral) and Subcarangiform (body-caudal) swimming (sensu Webb 1994; Blake 2004). A third intermediate mode involved subcarangiform swimming augmented by pectoral fin strokes (simultaneous pectoral-caudal). This pectoral-caudal mode was used widely within the chaetodontoids (with the exception of Pomacanthus and Hemitaurichthys, personal observation), and may therefore be referred to as Chaetodontiform swimming following Webb (1984). While differences in swimming mode utilization were largely a family-level phenomenon, a species-level analysis indicated that taxa were more accurately allocated to a particular mode at the genus-level, as previously suggested by Breder (1926). The defining characteristic by which taxa were allocated to a particular mode was the use of a specific fin category in more than $50 \%$ of observed individuals. While this resulted in most species within a family being assigned to a single mode, some families were split amongst modes, such as the Pomacanthidae with both pectoral-caudal (Centropyge and Pygoplites) and pectoral-swimming (Pomacanthus) taxa. Overwhelmingly, the labriform mode was used by the greatest number of coral reef fish taxa, with 70 species from 36 genera using this mode, most $(96 \%)$ of which were from three families: the Acanthuridae, Pomacentridae and Labridae.

Functionally, these three swimming modes may be separated into the two realms of median-paired fin (MPF) and body-caudal fin (BCF) propulsion. Labriform swimming using solely the pectoral fins represents an MPF form of propulsion where thrust is produced by oscillation of discrete fin appendages without body undulation. Conversely, the chaetodontiform and subcarangiform modes are essentially BCF in nature, using primarily the caudal fins and some degree of body undulation to produce thrust (Lindsey 1978; Webb 1994; Blake 2004). In terms of thrust kinematics, the two BCF forms of propulsion used by reef fishes in the present study are most likely to be associated with drag-based thrust from flexible body and caudal fin undulation, whereas taxa using the labriform mode may use oscillatory fin kinematics to exploit either drag- or lift-based forces through variations in the pattern of pectoral fin movement (Webb 1988; Walker and Westneat 2000; Blake 2004; but see Lauder 2000). Such differences in thrust exploitation may ultimately have consequences for the swimming speed performance of taxa, with lift-based thrust the most effective form of propulsion for maintaining high speeds, versus acceleration and slow sustained speeds using dragbased thrust (Vogel 1994; Walker and Westneat 2000).

\section{Swimming speed performance amongst modes}

Accordingly, swimming mode was found to have a profound influence on the swimming speed performance of taxa, as previously anticipated by biomechanical analyses of fish locomotion (Alexander 1967; Lindsey 1978; Webb 1988; Weihs 1989; Videler 1993). Striking differences were found in the swimming speed performance of taxa that manifest most strongly under field conditions to indicate two distinct functional groups of swimming mode and performance. Labriform (MPF) swimmers were generally faster than reef fishes using a caudal-swimming (BCF) gait, with average field speeds of up to $68.8 \mathrm{~cm} \mathrm{~s}^{-1}$ seen in MPFswimming species, in contrast with average speeds of $39.0 \mathrm{~cm} \mathrm{~s}^{-1}$ or less in species using either of the BCF modes (Table 2). Further comparisons of field-lab performance at the species-level indicated that field speeds in MPF taxa were on average, a remarkable $70 \%$ of their critical swimming speed, whereas species using a BCF mode maintained field speeds at around $50 \%$ of the speed attained in the critical swimming speed trials. Undoubtedly, BCF swimming fishes are capable of attaining high swimming speeds, as is evident from the considerable overlap in experimental speed performance among the three modes found in the present study. For instance, chaetodontiform taxa using augmented $\mathrm{BCF}$ propulsion attained close $\left(77.5 \mathrm{~cm} \mathrm{~s}^{-1}\right)$ to the maximum experimental speeds displayed by labriform taxa $\left(82.4 \mathrm{~cm} \mathrm{~s}^{-1}\right)$. Indeed, previous comparisons that have included reef fishes as well as pelagic and anadromous fishes have found that BCF fishes often attain faster speeds than MPF taxa of the same size (Walker and Westneat 2002; Blake 2004). However, findings from the present study confirm the hypothesis that MPF propulsion is capable of producing similar levels of speed performance as BCF taxa when fishes of similar lifestyle are compared. 
Table 3 Comparison of critical swimming speeds between settlement-stage and adults from seven reef fish families, with settlementstage performance indicated as a percentage of adult $U_{\text {crit }}$ speed

\begin{tabular}{|c|c|c|c|c|c|}
\hline \multirow[t]{2}{*}{ Family } & \multicolumn{2}{|c|}{ Mean $U_{\text {crit }} \pm \operatorname{SE}\left(\mathrm{cm} \mathrm{s}^{-1}\right)$} & \multicolumn{2}{|c|}{ Mean TL \pm SE $(\mathrm{mm})$} & \multirow{2}{*}{$\begin{array}{l}\text { Adult performance } \\
\text { at settlement }(\%)\end{array}$} \\
\hline & Settlement & Adult & Settlement & Adult & \\
\hline Acanthuridae & $50.5 \pm 1.4$ & $60.4 \pm 2.5$ & $35.4 \pm 0.5$ & $152.6 \pm 11.0$ & 83.6 \\
\hline Chaetodontidae & $48.8 \pm 2.3$ & $58.8 \pm 3.4$ & $15.5 \pm 0.7$ & $99.1 \pm 4.6$ & 83.0 \\
\hline Lutjanidae & $49.4 \pm 2.0$ & 59.3 & $26.2 \pm 0.8$ & 136.7 & 83.3 \\
\hline Nemipteridae & $34.3 \pm 2.3$ & 50.2 & $16.5 \pm 0.7$ & 118.7 & 68.3 \\
\hline Pomacanthidae & $20.7 \pm 3.1$ & $48.3 \pm 4.5$ & $16.4 \pm 0.2$ & $136.0 \pm 34.5$ & 42.9 \\
\hline Pomacentridae & $37.6 \pm 0.9$ & $49.8 \pm 2.4$ & $15.7 \pm 0.3$ & $87.1 \pm 5.4$ & 75.5 \\
\hline Serranidae & $31.5 \pm 3.2$ & $41.6 \pm 7.5$ & $21.4 \pm 0.6$ & $166.5 \pm 2.8$ & 75.7 \\
\hline Overall mean & $38.9 \pm 4.2$ & $52.6 \pm 2.7$ & $21.0 \pm 2.8$ & $128.1 \pm 10.7$ & $73.2 \pm 5.5$ \\
\hline
\end{tabular}

Note settlement-stage values taken from Fisher et al. (2005) were based on $U_{\text {crit }}$ trials with 2 min time intervals and 3 BL s ${ }^{-1}$ increments, versus $15 \mathrm{~min}$ and $0.5 \mathrm{BL} \mathrm{s}^{-1}$ increments used in the present study

Moreover, it appears that the routine speed performance of MPF species in the field is considerably higher than fishes using BCF propulsion, despite indications of similarly high-speed performance under laboratory conditions.

Previous comparisons of swimming capabilities in reef fishes at earlier life history stages also suggest an overriding influence of swimming mode on speed performance. Examinations of critical swimming performance in reef fishes at the settlement stage (total lengths $10-36 \mathrm{~mm}$ ) have revealed average and maximum swimming speeds of 38 and $101 \mathrm{~cm} \mathrm{~s}^{-1}$, respectively (Fisher et al. 2005). Family-level comparisons indicate that such settlement-stage swimming speed performances are equivalent to around $73 \%$ of the speeds attained as adults (Table 3). While these comparisons should be interpreted with caution due to the different swimming trial methodologies used in each study (Table 3), they suggest that reef fishes attain a large proportion of their swimming speed capabilities at a very early stage. Most intriguing, however, is the fact that larval fishes have been found to maintain field speeds at around $50 \%$ of their critical swimming speed performance (Fisher and Wilson 2004; Leis and Fisher 2006), which is a similar figure to that found in adult reef fishes using BCF propulsion in the present study. Could this similarity in field-experimental performance between early life history stages and adults be due to overriding limitations according to the form of propulsion? Indeed, larval fishes at this size generally use $\mathrm{BCF}$ propulsion, where drag-based forces predominate at these low Reynold's numbers (Webb and Weihs 1986; Webb 1988). Such parallels in the comparative speed performance of settlement-stage and adult reef fishes suggests some overriding limitations to BCF propulsion that restricts realised swimming speeds in the field to half their potential speed, regardless of life-history stage.
Energetics may be a key factor underlying these differences in comparative field-experimental performance amongst swimming modes. Whilst there is a paucity of empirical information on the comparative energetics of swimming modes, relationships between cost-of-transport and speed in some representative MPF and BCF taxa provide some insight. Reef fishes using a labriform (MPF) swimming mode have been found to display cost-of-transport minima spanning a broad range of swimming speeds (1.5-4.0 $\mathrm{BL} \mathrm{s}^{-1}$ ). Contrastingly, salmonids using a subcarangiform (BCF) mode display narrow minima at a relatively low speed $\left(0.8-1.5 \mathrm{BL} \mathrm{s}^{-1}\right)$, with steep increases in cost-of transport with increasing speed (Videler and Nolet 1990; Korsmeyer et al. 2002; Tolley and Torres 2002; Lee et al. 2003). Based on rates of oxygen consumption, these cost-of-transport relationships provide a relative measure of energy consumption during continuous swimming, for a set distance or period of time. Consequently, these relationships suggest that the labriform mode provides a particularly efficient means of swimming continuously over a broad range of speeds, whereas fishes using the subcarangiform (BCF) mode incur comparatively greater energetic costs at high speeds.

Indeed, labriform swimmers have been found to have a higher than average energetically optimum swimming speed (Korsmeyer et al. 2002), and empirical evidence on labriform taxa confirms a wide range of swimming speed performances and a propensity for higher field speeds than BCF taxa of the same size (Walker and Westneat 2000; Wainwright et al. 2002; this study). Greater energetic costs would be prohibitive for sustaining high speeds over the substantial time periods involved in daily swimming activities (Videler and Nolet 1990; Boisclair and Tang 1993; Pettersson and Hedenström 2000), which may explain why subcarangiform and chaetodontiform fishes in the present 
study displayed generally slower field speeds than labriform swimmers. While many labriform taxa also displayed similarly low speed performances, these taxa were those previously identified as species with rounded (low aspect-ratio) fins to exploit drag-based thrust (Wainwright et al. 2002; Fulton et al. 2005), which produces approximately five times less thrust at high speed when compared to taxa using the alternative form of lift-based flapping with tapered pectoral fins (Vogel 1994; Walker and Westneat 2000, 2002). While the origins of the lift-based kinematics in labriform swimming remains unclear, it appears to have been a key innovation that has provided the capacity for remarkably high field speeds, such as those recorded in the current study. Such advantages have also conferred significant ecological advantages, with lift-based labriform taxa occurring in almost every conceivable reef habitat, and often entirely dominating wave-swept habitats of challenging hydrodynamic conditions (Fulton and Bellwood 2005; Fulton et al. 2005).

Lab-field comparisons also revealed a number of positive outliers, with three species (Acanthurus lineatus and A. triostegus, Labriform; Chaetodon trifascialis, Chaetodontiform) displaying field performances markedly higher than expected from the relationship between $U_{\text {crit }}$ and field speeds for their respective modes. In fact, these three species displayed field speeds that were almost identical to the critical swimming speed estimates obtained during flow tank trials. While these species may have responded abnormally to the flow tank trials to produce such departures, no adverse behaviour was observed in these three species. Moreover, there is ecological evidence to suggest that these species may need to maintain high field speeds as a consequence of their similar lifestyles. All three species occupy wave-swept habitats of high water flow velocity (Fulton and Bellwood 2005), which may impose a higher than average demand for these species to maintain speeds in the upper range of their capabilities during daily activities.

\section{Critical swimming speed versus field performance}

Direct comparisons of critical swimming speed and field performance not only yielded crucial insights into the comparative performance of swimming modes, but also confirmed that lab-based measures provide a reliable predictor of performance in the field. While these findings support the suggestion that critical swimming speed $\left(U_{\text {crit }}\right)$ provides an ecologically relevant measure of swimming performance (Hammer 1995; Plaut 2001; Fisher et al. 2005), the specific relationship between this lab-based metric and field performance was strongly dependent on the swimming mode employed. In the three swimming modes examined, field speeds could be reliably estimated from a $70 \%$ adjustment of $U_{\text {crit }}$ values taken from labriform reef fishes, or a $50 \%$ adjustment of $U_{\text {crit }}$ values recorded for chaetodontiform and subcarangiform taxa.

Within a given mode, this disparity between values obtained by the $U_{\text {crit }}$ and field methods may largely be a reflection of the different time frames of each measurement technique. Although field speeds were measured over short time intervals ( $7.5 \mathrm{~s})$, these estimates are likely to be a good approximation of the average sustained performance of taxa, as they represent a snap-shot of speeds displayed over daily time scales (Videler 1993). In contrast, the $U_{\text {crit }}$ incremental velocity trials were measured over prolonged time scales (up to $249 \mathrm{~min}$ ), and may therefore provide estimates that are above actual levels of sustained speed performance (Hammer 1995; Plaut 2001). Notably, previous studies using gait-transition speed (sensu Drucker 1996) as the comparative performance measure have found an almost isometric relationship with field speed performance, with field speeds in labriform species being around $83 \pm 4 \%$ of their gait transition $\left(U_{\mathrm{pc}}\right)$ speed (Fulton et al. 2005). While this technique may not be readily applicable to swimming modes that lack distinct gait transitions (e.g., chaetodontiform), direct measurement of sustained swimming speeds from fixed-velocity endurance trials (>200 min) may provide estimates that more closely match field values. Nonetheless, evidence presented herein confirms the utility of $U_{\text {crit }}$ as a reliable labbased metric for comparing the relative swimming performances of taxa in a manner that closely reflects patterns of performance in the field.

Collectively, these findings not only highlight the overriding importance of swimming mode in shaping patterns of fish locomotion and ecology, they also reinforce the utility of laboratory studies for examining the swimming capabilities of fishes. While available evidence suggests that the variations in speed performance with swimming mode seen here have a primary basis in energetic efficiency, additional work is needed on the comparative energetics of swimming modes to clarify these issues. Furthermore, examination of complementary aspects of performance such as burst speeds and slow-speed manoeuvrability across the same range of taxa may also provide greater insight into the tradeoffs driving these differences in swimming speed performance amongst modes. Nonetheless, given the increasing evidence of high speed performance, manoeuvrability (Webb and Fairchild 2001; Weihs 2002) and efficiency (Walker and Westneat 2000; Korsmeyer 
et al. 2002) associated with MPF propulsion, it appears that modes such as labriform swimming provide a particularly versatile form of propulsion, well suited to the challenges of a demersal lifestyle on coral reefs.

Acknowledgments Many thanks to N. Cantin, K. Dunn, A. Hoey, N. Konow, T. Sunderland, A. Thomas and the staff of Lizard Island Research Station for field assistance. Thanks also to D. R. Bellwood, J. H. Choat, R. Fisher, M. Westneat, J. Walker and three anonymous reviewers for helpful comments. Financial support was provided by the Lizard Island Reef Research Foundation, Australian Coral Reef Society and James Cook University while the author was supported by a Nancy Vernon Rankine Scholarship. Experiments were approved by the JCU Animal Ethics Committee (no. A656_01). ARC Centre of Excellence for Coral Reef Studies contribution no. XXX.

\section{References}

Alexander R McN (1967) Functional design in fishes. Hutchinson University Press, London

Anderson JM, McGillis WR, Grosenbaugh MA (2001) The boundary layer of swimming fish. J Exp Biol 204:81-102

Beamish FWH (1978) Swimming capacity. In: Hoar WS, Randall DJ (eds) Fish physiology, vol VII. Academic, New York, pp 101-187

Bell WH, Terhune LDB (1970) Water tunnel design for fisheries research. Fish Res Board Can Tech Rep 195:1-69

Blake RW (2004) Fish functional design and swimming performance. J Fish Biol 65:1193-1222

Boisclair D, Tang M (1993) Empirical analysis of the swimming pattern on the net energetic cost of swimming in fishes. J Fish Biol 42:169-183

Breder CM (1926) The locomotion of fishes. Zool NY 4:159-297

Brett JR (1964) The respiratory metabolism and swimming performance of young sockeye salmon. J Fish Res Board Can 21:1183-1226

Castro-Santos T (2005) Optimal swim speeds for traversing velocity barriers: an analysis of volitional high-speed swimming behavior of migratory fishes. J Exp Biol 208:421-432

Drucker EG (1996) The use of gait transition speed in comparative studies of fish locomotion. Am Zool 36:555-566

Feldmeth CR, Jenkins TM (1973) An estimate of energy expenditure by rainbow trout (Salmo gairdneri) in a small mountain stream. J Fish Res Board Can 30:1755-1759

Fisher R (2005) Swimming speeds of larval coral reef fishes: impacts on self-recruitment and dispersal. Mar Ecol Prog Ser 285:223-232

Fisher R, Bellwood DR (2003) Undisturbed swimming behaviour and nocturnal activity of coral reef fish larvae. Mar Ecol Prog Ser 263:177-188

Fisher R, Wilson SK (2004) Maximum sustainable swimming speeds of nine species of late stage larval reef fishes. J Exp Mar Biol Ecol 312:171-186

Fisher R, Leis JM, Clark DL, Wilson SK (2005) Critical swimming speeds of late-stage coral reef fish larvae: variation within species, among species and between locations. Mar Biol 147:1201-1212

Fulton CJ, Bellwood DR (2005) Wave-induced water motion and the functional implications for coral reef fish assemblages. Limnol Oceanogr 50:255-264
Fulton CJ, Bellwood DR, Wainwright PC (2001) The relationship between swimming ability and habitat use in wrasses (Labridae). Mar Biol 139:25-33

Fulton CJ, Bellwood DR, Wainwright PC (2005) Wave energy and swimming performance shape coral reef fish assemblages. Proc R Soc Lond B 272:827-832

Greenacre MJ (1993) Correspondence analysis in practice. Academic, London

Hammer C (1995) Fatigue and exercise tests in fish. Comp Biochem Physiol 112A:1-20

Hartwell SI, Otto RG (1991) Critical swimming capacity of the Atlantic silverside, Menidia menidia L. Estuaries 14:218-221

Kitchell JF (1983) Energetics. In: Webb PW, Weihs D (eds) Fish biomechanics. Praeger, New York, pp 312-338

Korsmeyer KE, Steffensen JF, Herskin J (2002) Energetics of median and paired fin swimming, body and caudal fin swimming, and gait transition in parrotfish (Scarus schlegeli) and triggerfish (Rhinecanthus aculeatus). J Exp Biol 205:1253-1263

Krohn MM, Boisclar D (1994) Use of stereo-video system to estimate the energy expenditure of free-swimming fish. Can J Fish Aquat Sci 51:1119-1127

Lauder GV (2000) Function of the caudal fin during locomotion in fishes: kinematics, flow visualization, and evolutionary patterns. Am Zool 40:101-122

Lee CG, Farrell AP, Lotto A, MacNutt MJ, Hinch SG, Healey MC (2003) The effect of temperature on swimming performance and oxygen consumption in adult sockeye (Oncorhynchus nerka) and coho (O. kisutch) salmon. J Exp Biol 206:3239-3251

Leis J, Fisher R (2006) Swimming speed of settlement-stage reeffish larvae measured in the laboratory and in the field: a comparison of critical speed and in situ speed. Proc 10th Int Coral Reef Symp 438-445

Lighthill MJ (1969) Hydromechanics of aquatic propulsion: a survey. Annu Rev Fluid Mech 1:413-446

Lighthill MJ, Blake RW (1990) Biofluiddynamics of balistiform and gymnotiform locomotion. Part I. Biological background and analysis by elongated body theory. J Fluid Mech 212:187-207

Lindsey CC (1978) Form, function, and locomotory habitats in fish. In: Hoar WS, Randall DJ (eds) Fish physiology, vol VII. Academic, New York, pp 1-100

Lowe CG (1996) Kinematics and critical swimming speed of juvenile scalloped hammerhead sharks. J Exp Biol 199:2605-2610

Myrick CA, Cech JJ (2000) Swimming performance of four California stream fishes: temperature effects. Environ Biol Fish 58:289-295

Nelson JS (1994) Fishes of the world (3rd edn). Wiley, New York

Pettersson LB, Hedenström A (2000) Energetics, cost reduction and functional consequences of fish morphology. Proc R Soc Lond B 267:759-764

Plaut I (2000) Effects of fin size on swimming performance, swimming behaviour and routine activity of zebrafish Danio rerio. J Exp Biol 203:813-820

Plaut I (2001) Critical swimming speed: its ecological relevance. Comp Biochem Physiol 131A:41-50

Reist JD (1985) An empirical evaluation of several univariate methods that adjust for size variation in morphometric data. Can J Zool 63:1429-1439

Sokal RR, Rohlf FJ (1995) Biometry: the principles and practice of statistics in biological research (3rd edn). WH Freeman, New York 
Tolley SG, Torres JJ (2002) Energetics of swimming in juvenile common snook Centropomus undecimalis. Environ Biol Fish 63:427-433

Videler JJ (1993) Fish swimming. Chapman \& Hall, London

Videler JJ, Nolet BA (1990) Costs of swimming measured at optimum speed: scale effects, differences between swimming styles, taxonomic groups and submerged and surface swimming. Comp Biochem Physiol 97A:91-99

Vogel S (1994) Life in moving fluids: the physical biology of flow (2nd edn). Princeton University Press, Princeton

Vogel S, LaBarbera M (1978) Simple flow tanks for research and teaching. Bioscience 28:638-643

Wainwright PC, Bellwood DR, Westneat MW (2002) Ecomorphology of locomotion in labrid fishes. Environ Biol Fish 65:47-62

Walker JA, Westneat MW (2000) Mechanical performance of aquatic rowing and flying. Proc Soc Lond B 267:1875-1881

Walker JA, Westneat MW (2002) Performance limits of labriform propulsion and correlates with fin shape and motion. J Exp Biol 205:177-187

Webb PW (1975) Hydrodynamics and energetics of fish propulsion. Bull Fish Res Board Can 190:1-159
Webb PW (1984) Body form, locomotion and foraging in aquatic vertebrates. Am Zool 24:107-120

Webb PW (1988) Simple physical principles and vertebrate aquatic locomotion. Am Zool 28:709-725

Webb PW (1994) The biology of fish swimming. In: Maddock L, Bone Q, Rayner JMV (eds) Mechanics and physiology of animal swimming. Cambridge University Press, Cambridge, pp 45-62

Webb PW (1998) Swimming. In: Evans DH (ed) The physiology of fishes. CRC, New York, pp 3-24

Webb PW, Fairchild AG (2001) Performance and maneuverability of three species of teleostean fishes. Can J Zool 79:1866-1877

Webb PW, Weihs D (1986) Functional locomotor morphology of early life history stages of fishes. Trans Am Fish Soc 115:115-127

Weihs D (1989) Design features and mechanics of axial locomotion in fish. Am Zool 29:151-160

Weihs D (2002) Stability versus maneuverability in aquatic locomotion. Integr Comp Biol 42:127-134 